\title{
Determination of the reactivity ratios, sequence distribution and stereoregularity of butyl acrylate-methyl methacrylate copolymers by means of proton and carbon-13 NMR
}

\section{Citation for published version (APA):}

Aerdts, A. M., German, A. L., \& Velden, van der, G. P. M. (1994). Determination of the reactivity ratios, sequence distribution and stereoregularity of butyl acrylate-methyl methacrylate copolymers by means of proton and carbon-13 NMR. Magnetic Resonance in Chemistry, 32, S80-S88. https://doi.org/10.1002/mrc.1260321315

DOI:

10.1002/mrc. 1260321315

Document status and date:

Published: 01/01/1994

\section{Document Version:}

Publisher's PDF, also known as Version of Record (includes final page, issue and volume numbers)

\section{Please check the document version of this publication:}

- A submitted manuscript is the version of the article upon submission and before peer-review. There can be important differences between the submitted version and the official published version of record. People interested in the research are advised to contact the author for the final version of the publication, or visit the DOI to the publisher's website.

- The final author version and the galley proof are versions of the publication after peer review.

- The final published version features the final layout of the paper including the volume, issue and page numbers.

Link to publication

\footnotetext{
General rights

- You may freely distribute the URL identifying the publication in the public portal. follow below link for the End User Agreement:

www.tue.nl/taverne

\section{Take down policy}

If you believe that this document breaches copyright please contact us at:

openaccess@tue.nl

providing details and we will investigate your claim.
}

Copyright and moral rights for the publications made accessible in the public portal are retained by the authors and/or other copyright owners and it is a condition of accessing publications that users recognise and abide by the legal requirements associated with these rights.

- Users may download and print one copy of any publication from the public portal for the purpose of private study or research.

- You may not further distribute the material or use it for any profit-making activity or commercial gain

If the publication is distributed under the terms of Article 25fa of the Dutch Copyright Act, indicated by the "Taverne" license above, please 


\title{
Determination of the Reactivity Ratios, Sequence Distribution and Stereoregularity of Butyl Acrylate-Methyl Methacrylate Copolymers by Means of Proton and Carbon-13 NMR
}

\author{
A. M. Aerdts $\dagger$ and A. L. German* \\ Laboratory of Polymer Chemistry, Eindhoven University of Technology, P.O. Box 513, 5600 MB Eindhoven, The \\ Netherlands
}

G. P. M. van der Velden

DSM Research BV, P.O. Box 18, 6160 MD Geleen, The Netherlands

\begin{abstract}
The $400 \mathrm{MHz}$ proton NMR spectra of butyl acrylate (BA)-methyl methacrylate (MMA) copolymers prepared by free radical polymerization in solution at $323 \mathrm{~K}$ were used for the determination of the reactivity ratios. The reactivity ratios $r_{M}$ and $r_{B}$ calculated by the error-in-variables method are 2.279 and 0.395 , respectively. The methoxy region of the MMA proton signal resonance was found to be sensitive for MMA-centred sequences and a new assignment is proposed. The coisotacticity parameter $\sigma_{\mathrm{BM}}$ was calculated using a non-linear least-square procedure with relative error estimation based on the new assignment and was found to be 0.39 . The carbon-13 NMR spectra of the BA-MMA copolymers, in particular the carbonyl signal resonances, are sensitive for MMAand BA-centred configurational sequences. The same assignment is used as for the ethyl acrylate-methyl methacrylate copolymer.
\end{abstract}

KEY wORDS NMR ${ }^{1} \mathrm{H}$ NMR ${ }^{13} \mathrm{C}$ NMR Butyl acrylate Methyl methacrylate Copolymers

\section{INTRODUCTION}

Acrylate and methacrylate copolymers and also multi(meth)acrylate polymers are extensively used as coating membranes, binder latices, adhesives and sealants, especially owing to the great variety of glass-transition temperatures $\left(T_{\mathrm{g}}\right)$. Comparing, e.g., the system ethyl acrylate-methyl methacrylate (EA-MMA) with the system butyl acrylate-methyl methacrylate (BA-MMA), it is well known, that the $T_{\mathrm{g}}$ of the latter system is substantially lower than that of the former, which leads to a more flexible system in the second case. ${ }^{1}$ Sometimes, the above-mentioned homo-, co- and multi-polymers contain copolymerized species for more polar comonomers such as acrylic acid (AA) or methacrylic acid (MAA). ${ }^{2}$

In binder latices, especially the system BA-MMA is used in order to bind the filler materials such as $\mathrm{TiO}_{2}{ }^{1}$ However, no extensive study is available in which the microstructure was studied using ${ }^{1} \mathrm{H}$ or ${ }^{13} \mathrm{C}$ NMR spectroscopy. Recently an NMR review was published, ${ }^{3}$ but little attention has been paid to the above-mentioned systems, although it is well known that ${ }^{1} \mathrm{H}$ and ${ }^{13} \mathrm{C}$

* Author to whom correspondence should be addressed.

+ Present address: Laboratory of Macromolecular Structural Chemistry, Department of Chemistry, Catholic University of Leuven, Celestijnenlaan 200F, B-3001 Heverlee, Belgium.
NMR are particular effective in the determination of the intramolecular chain structure.

It is still astonishing that, in retorespect, the most complex system was studied first by a combination of ${ }^{1} \mathrm{H}$ and ${ }^{13} \mathrm{C}$ NMR, i.e. the system MMA-MAA was studied in detail by Klesper et al. ${ }^{4}$ in the mid-1970s. Much later this system was re-examined by Llauro et al. ${ }^{5}$ via ${ }^{13} \mathrm{C}$ NMR in pyridine- $d_{5}$ solvent. The very complex splittings in the carbonyl ${ }^{13} \mathrm{C}$ NMR spectra were interpreted using pentad configurational patterns and compositional triads.

Increasing the chain length of the ester group of the MMA unit, the homopolymer MMA-MMA (PMMA), ${ }^{3}$ extensively studied by ${ }^{13} \mathrm{C}$ NMR, can be left out and the following system is ethyl methacrylate-methyl methacrylate (EMA-MMA). This system has been studied by ${ }^{13} \mathrm{C}$ NMR by Brar's group. ${ }^{6}$ In this case, the carbonyl pattern was analysed in compositional triads, neglecting any effects of configurational splittings. A related system, i.e. ethyl methacrylate-butyl methacrylate (EMA-BMA), ${ }^{7}$ was studied by the same group and using the same analysis of the observed carbonyl pattern. Apparently, the system propyl methacrylatemethyl methacrylate (PMA-MMA) has not been studied, but the following homologue of the series, methacrylate-methacrylate has been studied again by Brar's group, i.e. BMA-MMA. ${ }^{7}$ Again, emphasis was given to the analysis of the carbonyl pattern observed in the same NMR solvent $\mathrm{CDCl}_{3}$ at $25^{\circ} \mathrm{C}$ as used for the previously mentioned systems EMA-MMA and EMA- 
Table 1. Overview of co-methacrylates and acrylate-methacrylate and co-acrylate copolymers characterized in terms of compositional triads (sequences) and configuration (tacticity) by means of NMR

\begin{tabular}{|c|c|c|c|c|}
\hline System & NMR. & Sequences & Tacticity & Ref. \\
\hline MAA-MMA & $\begin{array}{l}{ }^{1} \mathrm{H}, \\
{ }^{13} \mathrm{C}\end{array}$ & $\begin{array}{l}\text { Yes } \\
\text { Yes }\end{array}$ & $\begin{array}{l}\text { No } \\
\text { Yes }\end{array}$ & $\begin{array}{l}4 \\
5\end{array}$ \\
\hline EMA-MMA & ${ }^{13} \mathrm{C}$ & Yes & No & 6 \\
\hline PMA-MMA & No & & & - \\
\hline BMA-MMA & ${ }^{13} \mathrm{C}$ & Yes & $\mathrm{No}^{\mathrm{a}}$ & 7 \\
\hline 2naMA-MMA & ${ }^{1} \mathrm{H}$ & Yes & Yes & 8 \\
\hline GMA-MMA & No & & & - \\
\hline EMA-BMA & ${ }^{13} \mathrm{C}$ & Yes & $\mathrm{No}^{\mathrm{a}}$ & 7 \\
\hline MAA-(dma) MA & ${ }^{13} \mathrm{C}$ & Yes & No & 9 \\
\hline$(t n b t) M A-M M A$ & ${ }^{13} \mathrm{C},{ }^{119} \mathrm{Sn}$ & Yes & No & 10 \\
\hline AA-MMA & ${ }^{13} \mathrm{C}$ & Yes & No & 11 \\
\hline MA-MMA & ${ }^{1} \mathrm{H}$ & Yes & Yes & 12,13 \\
\hline EA-MMA & ${ }^{13} \mathrm{C}$ & Yes & Yes & 14 \\
\hline PA-MMA & No & & & - \\
\hline \multirow[t]{2}{*}{$B A-M M A$} & ${ }^{7} \mathrm{H}$ & Yes & Yes & 15 \\
\hline & ${ }^{1} \mathrm{H},{ }^{13} \mathrm{C}$ & Yes & Yes & This work \\
\hline HA-MMA & ${ }^{13} \mathrm{C}$ & Yes & & 16 \\
\hline PhA-MMA & ${ }^{1} \mathrm{H}$ & Yes & Yes & 17 \\
\hline (i) BA-GMA & ${ }^{13} \mathrm{C}$ & Yes & No & 18 \\
\hline AA-MA & No & & & - \\
\hline EA-MA & No & & & - \\
\hline (i) PA-MA & No & & & - \\
\hline BA-MA & ${ }^{13} \mathrm{C}$ & No effects & & 19 \\
\hline
\end{tabular}

BMA. The splitting was again exclusively interpreted in terms of compositional triads. Still larger homologues have been studied, e.g. the system 2-naphthyl methacrylate-methyl methacrylate. ${ }^{8}$ However, a sequence analysis has not been performed. Apparently, a system such as glycidyl methacrylate-methyl methacrylate (GMA-MMA) has not been examined via sequence analysis using either ${ }^{13} \mathrm{C}$ NMR or ${ }^{1} \mathrm{H}$ NMR.

Some related systems have been studied via sequence analysis, such as the systems methacrylic acid(dimethylamino)ethyl methacrylate ${ }^{9}$ and tri-n-butyltin methacrylate-methyl methacrylate. ${ }^{10}$ The latter system has been studied using ${ }^{13} \mathrm{C}$ and ${ }^{119} \mathrm{Sn}$ NMR. In this case the observed patterns were again interpreted in terms of mixed configurational and compositional triads.

Switching over to the acrylate-methacrylate systems, to our knowledge only one study has been published using both ${ }^{1} \mathrm{H}$ and ${ }^{13} \mathrm{C}$ NMR, which dealt with a sequence analysis for the parent system acrylic acidmethyl methacrylate (AA-MMA). Brar's group ${ }^{11}$ considered the carbonyl splittings patterns in the ${ }^{13} \mathrm{C}$ NMR spectra, resolving these exclusively with $\mathrm{AA}$ and MMA compositional triads. The first homologue of the acrylate-methacrylate series, i.e. methylacrylate-methyl methacrylate (MA-MMA) was studied in the mid-1970s by Mori et al. ${ }^{12}$ and recently by Lopez-Gonzalez et al. ${ }^{13}$ Both performed a sequence analysis using ${ }^{1} \mathrm{H}$ NMR. No ${ }^{13} \mathrm{C}$ NMR analysis has been published. The next higher homologue, i.e. EA-MMA, has been extensively studied via ${ }^{13} \mathrm{C}$ NMR by San Roman and Valero. ${ }^{14}$ In their study, the coisotacticity parameter, i.e. $\sigma=0.41$, was derived from an analysis of the quaternary carbon and/or methyl patterns. This parameter was used subsequently to unravel the complex carbonyl splitting patterns observed for this system. Their system was interpreted in terms of a mixed configurational/ compositional triad pattern. However, the analysis of the coisotacticity parameter is not completely clear and certainly not applicable to the current system, i.e. BA-MMA. Similarly to the methacrylate series, the propylacrylate-methyl methacrylate (PA-MMA) system has not been studied by ${ }^{13} \mathrm{C}$ NMR. The next homologue (BA-MMA) has been studied by Brosse $e t$ al. ${ }^{15}$ via ${ }^{1} \mathrm{H}$ NMR. They showed that the methoxy resonances of the MMA unit are sensitive to different configurational sequences. However, initial experiments on this system at substantially higher fields, performed in our laboratory, have shown considerably more splittings to occur, leading us to a re-examination of this system via both ${ }^{1} \mathrm{H}$ and ${ }^{13} \mathrm{C}$ NMR. Apparently this system has not been studied by ${ }^{13} \mathrm{C}$ NMR. However, the spectra of this system are expected to show a strong resemblance to the spectra of the system EA-MMA, studied by San Roman and Valero. ${ }^{14}$ Attention has also been paid to some larger homologues of this series, i.e. the system heptyl acrylate-methyl methacrylate ${ }^{16}$ in a study of reactivity ratios, and phenyl acrylate-methyl methacrylate by San Roman and Madruga ${ }^{17}$ in a study of stereochemical configurations.

The systems BA-GMA and i-BA-GMA have also been studied via ${ }^{13} \mathrm{C}$ NMR by Dhal et al. ${ }^{18}$ Again, attention was mainly paid to an analysis of the splitting patterns of the carbonyl signals, interpreting these as 
only split by compositional sequence triad distribution effects.

Considering co-acrylic systems, to our knowledge no systematic studies have been published which deal with the systems AA-MA, EA-MA and i-PA-MA. In a thesis, ${ }^{19}$ the system BA-MA was studied by means of ${ }^{1} \mathrm{H}$ and ${ }^{13} \mathrm{C}$ NMR. However, no sequence-induced splittings were observed in these spectra.

Reviewing the situation, mixed results have been reported for (meth)acrylate-related systems. For methacrylate-related systems effects of splittings induced by a combination of configurational and compositional effects have been well documented for the systems MAA-MMA ${ }^{1}$ and EA-MMA ${ }^{14}$ in the analysis of the carbonyl patterns in the respective ${ }^{13} \mathrm{C}$ NMR spectra. In all other systems, only sequence-induced splittings have been taken into account, and no splittings have been found to occur in the co-acrylic systems. In Table 1 a summary is given of the systems discussed.

It was the intention in this study to analyse the ${ }^{1} \mathrm{H}$ and ${ }^{13} \mathrm{C}$ NMR spectra of the commercially important system BA-MMA. The procedure to be followed was to determine the coisotacticity parameter from the methoxy-induced splitting of the MMA unit in the ${ }^{1} \mathrm{H}$ NMR spectra, taking into account recent results for related systems such as styrene-MMA, ${ }^{20}$ styrene-MA ${ }^{21}$ and styrene-EMA. ${ }^{22}$ The necessary reactivity ratios were also measured via a new approach. Subsequently, the ${ }^{13} \mathrm{C}$ NMR spectra of the BA-MMA system were studied, mainly devoted to an analysis of the carbonyl patterns.

\section{EXPERIMENTAL}

\section{Copolymer synthesis}

The monomers butyl acrylate and methyl methacrylate (Merck) were distilled at reduced pressure under nitrogen. The middle fraction of the distillate was collected and used. The free radical initiator azobisisobutyronitrile (AIBN) (Fluka) was recrystallized once from methanol. The solution-synthesized copolymers were prepared in a $100 \mathrm{ml}$ glass vessel, thermostated at 323 $\mathrm{K}$. The total monomer concentration was $3 \mathrm{~mol} \mathrm{l}^{-1}$ in toluene. The total conversion was determined by means of solid weight, and amounted to a maximum of $6 \mathrm{wt} \%$. The initiator concentration was $8 \mathrm{mmol}^{-1}$. To isolate and purify the copolymer, the reaction mixture was poured into a tenfold excess of cold hexane. The final product was dried at $328 \mathrm{~K}$ in a vacuum oven for at least $72 \mathrm{~h}$ at $10^{-5}$ Torr $(1$ Torr $=133.3 \mathrm{~Pa})$.

\section{NMR}

${ }^{1} \mathrm{H}$ NMR spectra were recorded with a (Bruker AM 400) $400 \mathrm{MHz}$ spectrometer at $393 \mathrm{~K}$, using 1,2,4-trichlorobenzene as a solvent and 1,1,2,2-tetrachloroethane- $d_{2}$ as locking agent. The spectra were obtained using a spectral width of $6024 \mathrm{~Hz}$, and acquisition time of $2.7 \mathrm{~s}$, a flip angle of $45^{\circ}$ and a pulse delay of $5 \mathrm{~s}$ after accumulating 240 scans, using a sample con- centration of $1 \%(\mathrm{w} / \mathrm{v})$. The digital resolution was 0.368 $\mathrm{Hz}$ per point, corresponding to a data length of $32 \mathrm{~K}$. The chemical shift is referred to $\mathrm{C}_{6}-\mathrm{H}-7.35 \mathrm{ppm}$.

The ${ }^{13} \mathrm{C}$ NMR spectra were recorded at $100 \mathrm{MHz}$ with the same spectrometer at $393 \mathrm{~K}$. The sample concentration was $10 \%(\mathrm{w} / \mathrm{v})$ in 1,2,4-trichlorobenzene. 1,1 , 2,2-Tetrachloroethane- $d_{2}$ was used as locking agent. The spectra were obtained accumulating 12000 scans with a digital resolution of $1.526 \mathrm{~Hz}$ per point, corresponding to a spectral width of $25000 \mathrm{~Hz}$ and a data length of $32 \mathrm{~K}$. The flip angle and the pulse delay were $45^{\circ}$ and $4 \mathrm{~s}$, respectively. The chemical shift is refered to C-5-127.8 ppm (of 1,2,4-trichlorobenzene).

In performing quantitative NMR measurements via compositional sequence and tacticity placements, one must take into account differences in spin-lattice relaxation times $\left(T_{1}\right)$. No differential $T_{1} \mathrm{~s}$ were observed and for the carbonyl signals differential NOEs were assumed not to occur. The relative peak areas were measured by planimetry. The inaccuracy in determining the peak areas from the NMR spectra was about $8 \%$.

\section{Calculations}

The reactivity ratios were determined by a non-linear least-squares fit calculation. It is known as the error-invariables (EVM) method, ${ }^{23}$ where the errors in both the dependent and independent variables are taken into account.

\section{RESULTS AND DISCUSSION}

The ${ }^{13} \mathrm{C}$ NMR spectra lead to a superposition of signals of the MMA and BA system. As is evident from visual inspection of the ${ }^{13} \mathrm{C}$ NMR spectral region between 15 and $60 \mathrm{ppm}$ (see Fig. 1), extensive overlapping signals occur, e.g. between the $\alpha-\mathrm{CH}_{3}$ main chain group of the MMA unit and the $\mathrm{CH}_{2}$ adjacent to the $\mathrm{CH}_{3}$ of the $\mathrm{BA}$ unit, therefore excluding any detailed analysis of this region. Such a spectral overlap is not present in the EA-MMA system. ${ }^{14}$

A similar overlapping region is seen for resonances belonging to the quaternary carbon of the MMA unit. In this case, however, in our opinion, no differences occur for the EA-MMA and BA-MMA systems (compare, e.g., Fig. 1 in Ref. 14 with Fig. 1 here). Nevertheless, from these quaternary signals the coisotacticity parameter was calculated for the EA-MMA system. We prefer, in our system, to calculate this parameter from the ${ }^{1} \mathrm{H}$ NMR spectra. The value of this parameter is used in order to assign the various carbonyl signals of the BA-MMA system. As a starting point, the signal assignments of San Roman and Valero ${ }^{14}$ are used, because we do not expect large variations on going from the EA-MMA to the BA-MMA system. This observation is corroborated by mutual comparison of the carbonyl patterns observed for both systems (compare Fig. 7 in Ref. 14 and Fig. 2 here). 

$\mathrm{CH}_{3}$
$-\stackrel{Y}{C}-\mathrm{CH}_{2}-$
$\mathrm{C}=\mathrm{O}$
$\stackrel{\circ}{\mathrm{C}}$
(MMA)
Oे
$\mathrm{H}_{3}$
$\sqrt{10}$
- $\underset{\mathrm{C}=\mathrm{CH}}{\mathrm{C}}-\stackrel{(\mathrm{MC}}{\mathrm{CH}_{2}}-$
(1) $\mathrm{CH}_{2}$
(2) $\mathrm{CH}_{2}$
(3) $\mathrm{CH}_{2}$
(4) $\mathrm{CH}_{3}$

(1)
(BA)

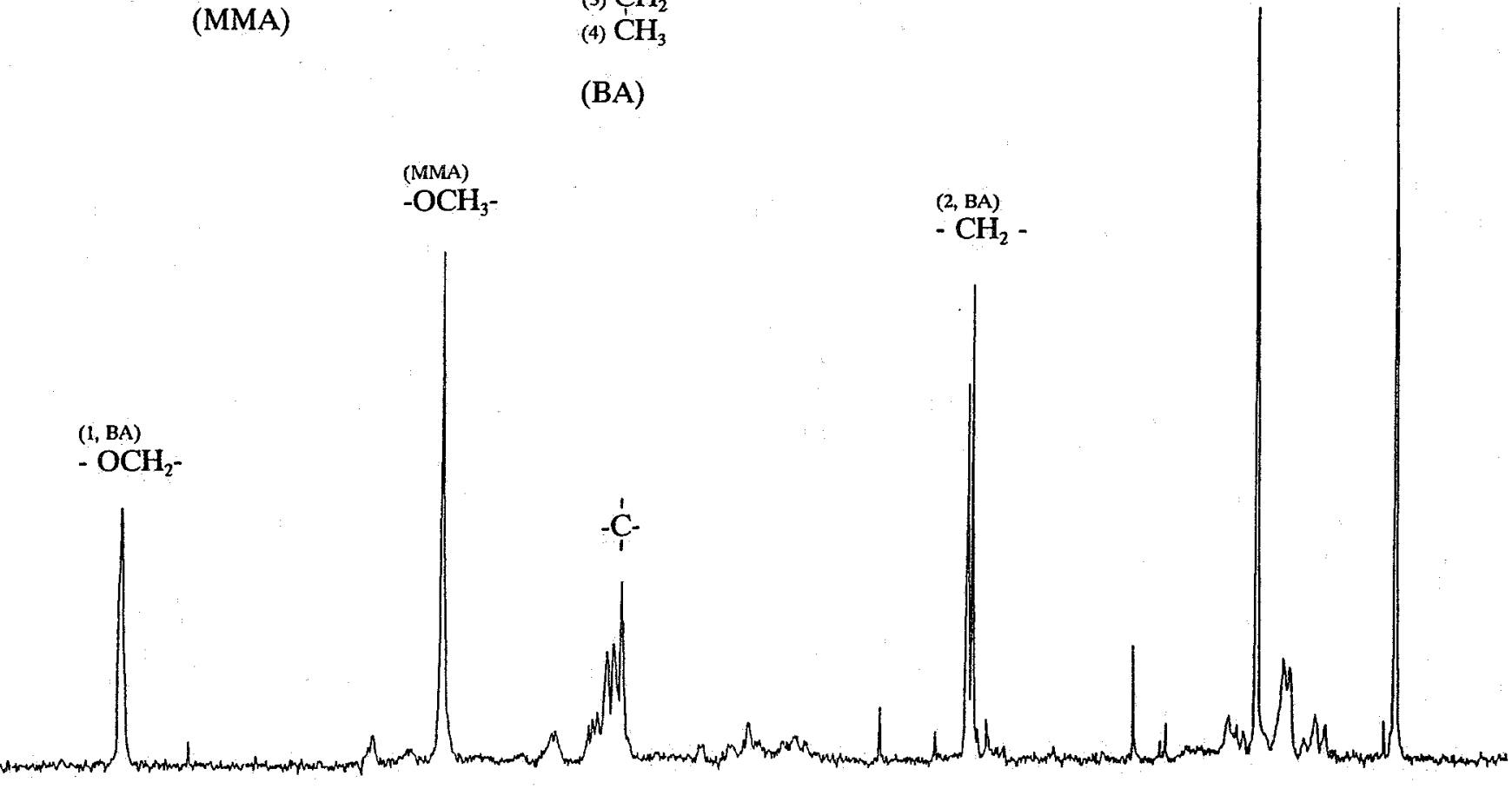

60

50

(ppm)

$(3, \mathrm{BA}) \quad(4, \mathrm{BA})$

$-\mathrm{CH}_{2}-\quad-\mathrm{CH}_{3}-$

Figure 1. $100 \mathrm{MHz}{ }^{13} \mathrm{C}$ NMR spectrum of a $B A-M M A$ copolymer with $F_{M}=0.69$, showing only region from 70 to 0 ppm.

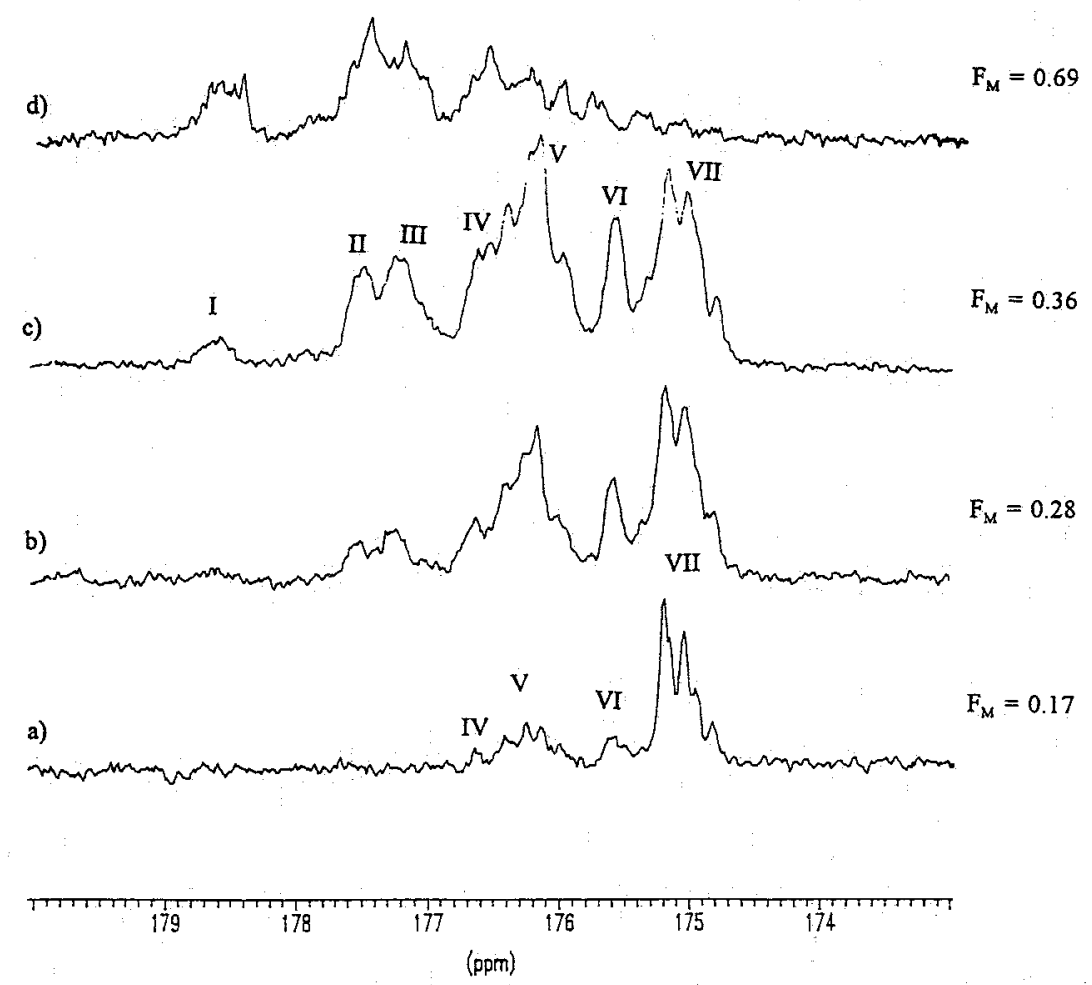

Figure 2. Expanded $100 \mathrm{MHz}{ }^{13} \mathrm{C}$ NMR spectra of the carbonyl carbon resonance signals of MMA- and BA-centred sequences. 


\section{${ }^{1} \mathrm{H}$ NMR}

Copolymer composition. The average copolymer composition (mole fraction of methyl methacrylate $F_{M}$ ) can be readily obtained by using the equation

$$
F_{M}=\frac{2 A_{1}}{2 A_{1}+3 A_{2}},
$$

where $A_{1}$ and $A_{2}$ represent the total peak areas of the proton resonances $-\mathrm{OCH}_{3}-$ of the MMA unit and of the $-\mathrm{OCH}_{2}-$ of the $\mathrm{BA}$ unit, respectively. This is shown in Fig. 3, where a $400 \mathrm{MHz}$ spectrum of a BA-MMA copolymer $\left(F_{M}=0.36\right)$ is shown. The composition of copolymers as determined by ${ }^{1} \mathrm{H}$ NMR along with the feed composition is given in Table 2 .

Reactivity ratios. The reactivity ratios for the AIBNinitiated system at $323 \mathrm{~K}$ were determined according to EVM method. ${ }^{23}$ The resulting reactivity ratio estimates were $r_{M}=2.279$ and $r_{B}=0.395$. The $95 \%$ posterior

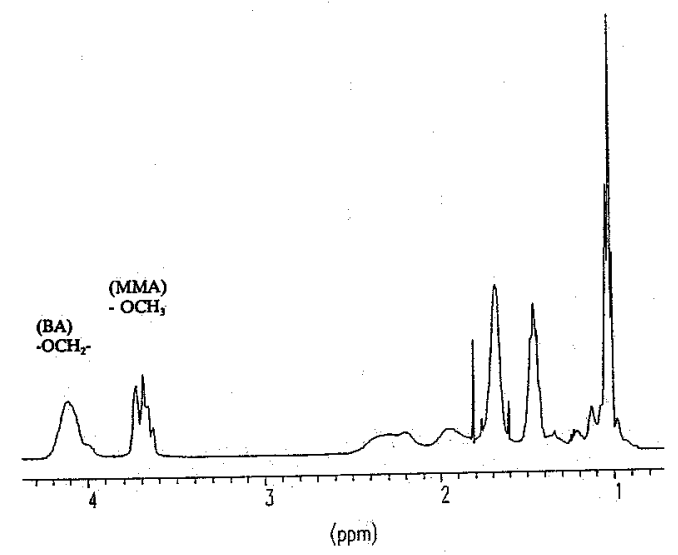

Figure 3. $400 \mathrm{MHz}$ proton NMR spectrum of a BA-MMA copolymer with $F_{M}=0.36$.

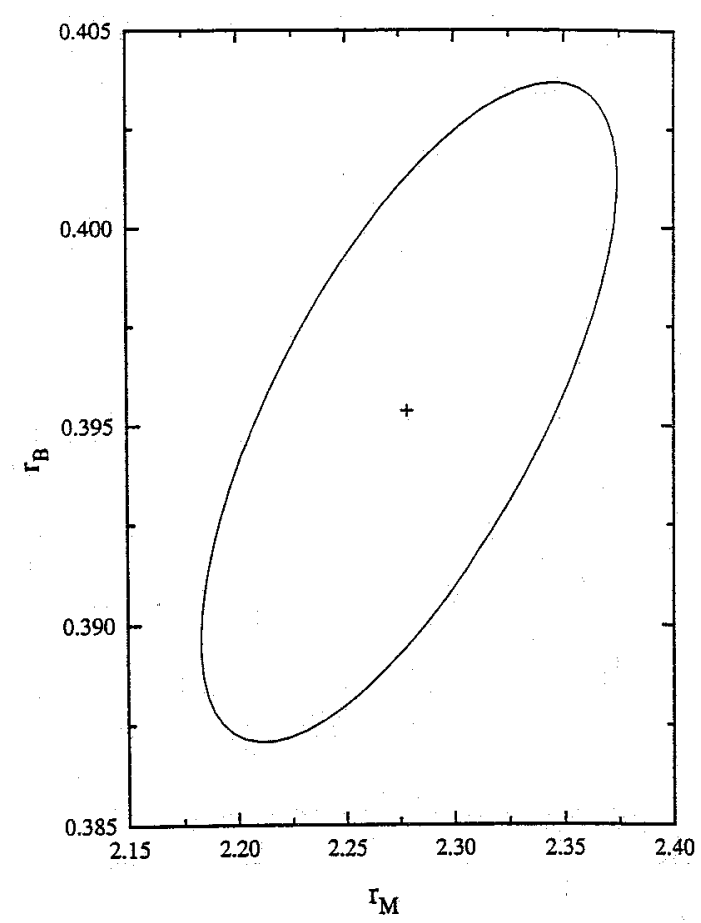

Figure 4. $95 \%$ posterior probability contour for estimated $r_{\mathrm{B}}$ and $r_{M}$ values.

probability contour is shown in Fig. 4. In Fig. 5 the experimental and theoretical relationships between the molar feed composition and the copolymer composition are presented.

Assignment of the methoxy proton (MMA). In Fig. 6, some of the expanded $400 \mathrm{MHz}$ proton NMR spectra of BA-MMA copolymers with different feed compositions are shown. Expansions of the methoxy region are shown since in particular this region displays additional

Table 2. Normalized peak areas of the methoxy proton of the MMAcentred triads of BA-MMA copolymers obtained by low conversion batch solution processes ${ }^{\mathbf{a}}$

\begin{tabular}{clllllll}
$f_{M}$ & \multicolumn{1}{c}{$F_{\mathrm{M}}$} & \multicolumn{1}{c}{$A$} & \multicolumn{1}{c}{$B$} & \multicolumn{1}{c}{$C$} & \multicolumn{1}{c}{$D$} & \multicolumn{1}{c}{$E$} & \\
0.036 & 0.17 & 0.26 & 0.13 & 0.30 & 0.10 & 0.21 & Exp. \\
& 0.143 & 0.28 & 0.14 & 0.358 & 0.09 & 0.132 & Calc. \\
0.125 & 0.28 & 0.22 & 0.19 & 0.31 & 0.16 & 0.12 & Exp. \\
& 0.261 & 0.211 & 0.226 & 0.270 & 0.145 & 0.147 & Calc. \\
0.184 & 0.36 & \multicolumn{2}{c}{0.40} & 0.28 & 0.21 & 0.11 & Exp. \\
& 0.355 & 0.162 & 0.274 & 0.208 & 0.175 & 0.181 & Calc. \\
0.300 & 0.53 & & 0.549 & & & 0.451 & Exp. \\
& 0.507 & & 0.522 & & & 0.478 & Calc. \\
0.400 & 0.595 & & 0.44 & & & 0.56 & Exp. \\
& 0.613 & & 0.426 & & & 0.574 & Calc. \\
0.408 & 0.629 & & 0.469 & & & 0.535 & Exp. \\
& 0.620 & & 0.418 & & & 0.582 & Calc. \\
0.512 & 0.69 & & 0.396 & & & 0.604 & Exp. \\
& 0.711 & & 0.328 & & & 0.672 & Calc. \\
0.779 & 0.854 & & 0.16 & & & 0.84 & Exp. \\
& 0.890 & & 0.131 & & & 0.869 & Calc. \\
& 0.69 & & & &
\end{tabular}

a Predicted relative areas calculated using the ultimate model for low conversion copolymers, and Ref. $r_{M}=2.279$ and Ref. $r_{B}=0.395, \sigma_{B M}=0.39$ and the appropriate assignment for various initial feed compositions $f_{M}$. 


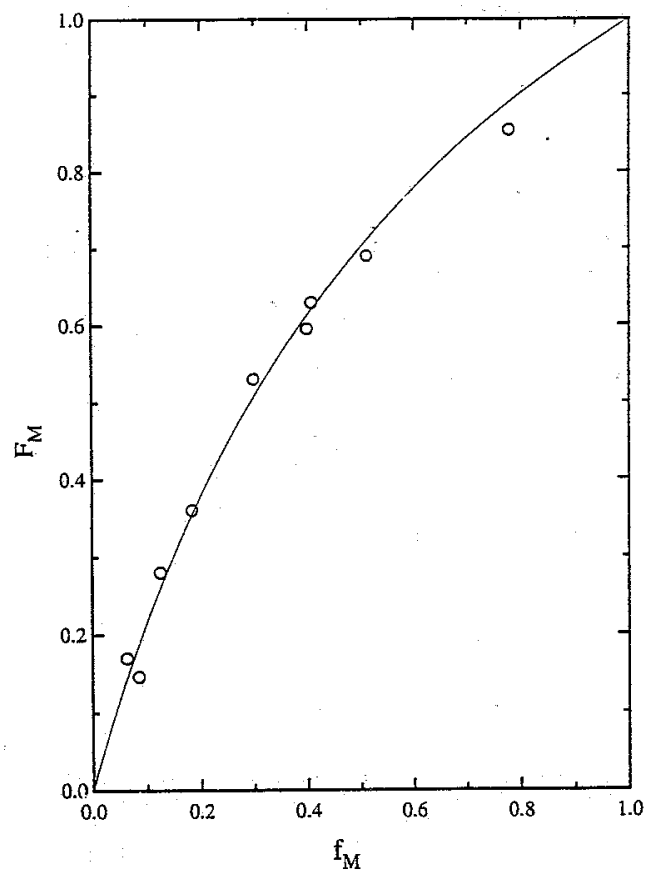

Figure 5. Relationship between copolymer feed composition $f_{\mathrm{M}}$ and the average copolymer composition $F_{\mathrm{M}}$.

splitting due to combined configurational (=tacticity) and compositional sequence effects. ${ }^{15}$ Brosse et al. ${ }^{15}$ published the $100 \mathrm{MHz}$ proton NMR spectra of BA-MMA copolymers and assigned the split methoxy resonance of the MMA-centred triads as follows:

$$
\begin{aligned}
\delta_{3.65 \mathrm{ppm}}= & (1-\sigma)^{2} \mathrm{BMB}+\left(1-\sigma_{\mathrm{MM}}\right)(1-\sigma) \mathrm{MMB} \\
\delta_{3.60 \mathrm{ppm}}= & \mathrm{MMM}+\left[\sigma_{\mathrm{MM}} \sigma+\sigma_{\mathrm{MM}}(1-\sigma)\right. \\
& \left.+\left(1-\sigma_{\mathrm{MM}}\right) \sigma\right] \mathrm{MMB} \\
& +[\sigma \sigma+2 \sigma(1-\sigma)] \mathrm{BMB}
\end{aligned}
$$

where $\sigma$ is $\sigma_{\mathrm{BM}}$, the coisotacticity parameter (meso configuration between a BA and a MMA unit) and $\sigma_{\mathrm{MM}}$ is the isotacticity (meso configuration between two MMA units). An MMM sequence shows no tacticity since in the proton NMR spectrum of PMMA only a single peak signal exists at $3.6 \mathrm{ppm}$.

However, the improved resolution of the methoxy region in proton NMR spectra recorded at higher magnetic fields (in our case at $400 \mathrm{MHz}$ ) leads to a significantly more observable fine structure. This allows us to assign a more accurate assignment of the methoxy protons. As shown in Fig. 6(a) $\left(F_{M}=0.17\right)$, the methoxy resonance signal of the MMA-centred units has been reinterpreted in terms of five major peak signals, each of which is attributed to an individual or two MMAcentred sequences. This has not been observed before because Brosse $e$ al. $^{15}$ showed the spectra of BA-MMA of $F_{M}=0.42$ and of higher fractions of MMA in the copolymer. It has been found (Fig. 6) that no additional splitting can be observed in copolymers with fractions of MMA higher than 0.3.
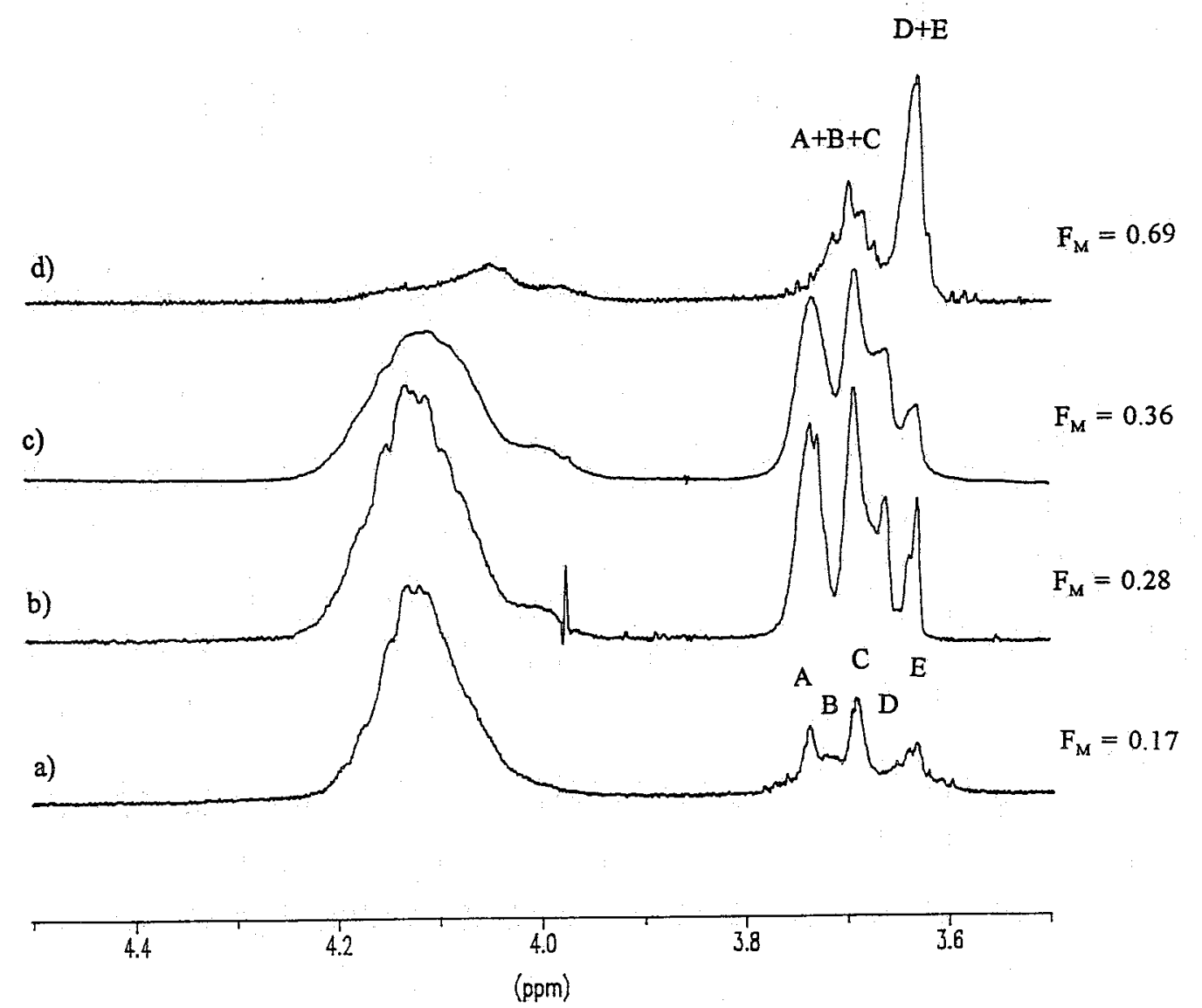

Figure 6. Expanded $400 \mathrm{MHz}$ proton NMR spectra showing the methoxy region of four different BA-MMA copoiymers. 


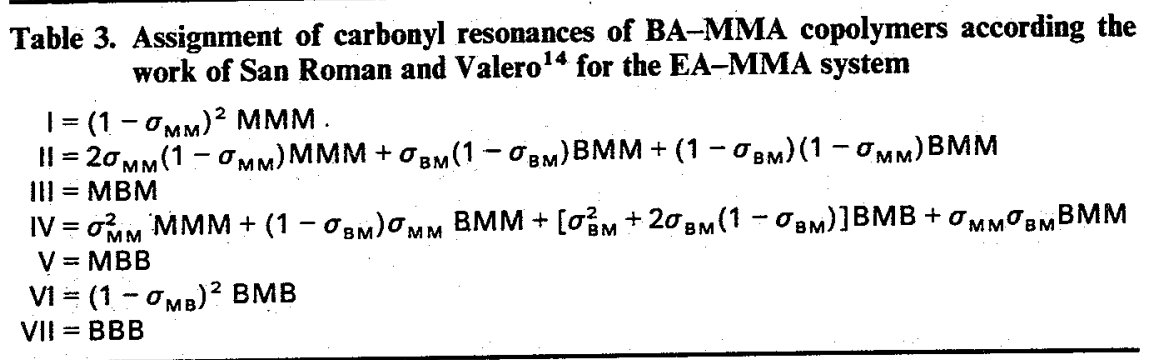

The assignment of the peak signals is as follows:

$$
\begin{array}{ll}
\mathrm{A}=(1-\sigma)^{2} \mathrm{BMB} & (\delta=3.74 \mathrm{ppm}) \\
\mathrm{B}=(1-\sigma) \mathrm{MMB} & (\delta=3.72 \mathrm{ppm}) \\
\mathrm{C}=2 \sigma(1-\sigma) \mathrm{BMB} & (\delta=3.69 \mathrm{ppm}) \\
\mathrm{D}=\sigma \mathrm{MMB} & (\sigma=3.67 \mathrm{ppm}) \\
\mathrm{E}=\sigma^{2} \mathrm{BMB}+\mathrm{MMM} & (\delta=3.63 \mathrm{ppm})
\end{array}
$$

where $\sigma$ is the coisotacticity parameter. No tacticity effects of two adjacent MMA units are assumed to occur. It is very clear in Fig. 6(a) that peaks A, C and E belong to the BMB triad. The MMM triad is resonating at $3.63 \mathrm{ppm}$, i.e. also peak E. Hence peaks B and D are subsequently assigned to the BMM triads. A BA unit in racemic configuration towards the MMA-centred unit gives more deshielding than a BA unit in meso configuration, so the $(1-\sigma)$ MMB resonates at lower field than $\sigma$ MMB. $^{15}$ It is unclear from where the intensities next to peaks $A$ and $E$ in Fig. 6(a) arise. These are probably artifacts.

The clear peak splitting does not hold over the entire range of BA-MMA copolymers, as can be seen in Fig. 6. In Fig. 6(b) we still can see five peak signals. In Fig. 6(c) only four peak signal areas $(A+B, C, D, E)$ can be observed and at higher fractions of MMA in the copolymer we can distinguish only two peak signals
$(A+B+C, D+E)$. Because of the accuracy the peak assignment at high mole fractions of MMA in the copolymer is combined as follows:

$$
\begin{aligned}
& \delta_{3.72 \mathrm{ppm}}=\mathrm{A}+\mathrm{B}+\mathrm{C} \\
& \delta_{3.63 \mathrm{ppm}}=\mathrm{D}+\mathrm{E}
\end{aligned}
$$

Coisotacticity parameter. The coisotacticity parameter is calculated using a non-linear least-squares procedure with relative error estimation ${ }^{24}$ based on the current assignment. $\mathrm{A} \sigma$ of $0.39 \pm 0.05$ was found, which is in agreement with the coisotacticity parameter of the related EA-MMA system, which amounted 0.41 (measured by ${ }^{13} \mathrm{C}$ NMR). ${ }^{14}$

Peak areas and sequence distribution. In Table 2, the molar feed composition $f_{\mathrm{M}}$, the average copolymer composition $F_{\mathrm{M}}$, the experimentally observed peak areas and the calculated peak areas are given. The theoretical triads can be calculated by assuming the validity of the ultimate model $^{25}$ (Alfrey/Mayo kinetics $=$ first-order

\begin{tabular}{|c|c|c|c|c|c|c|c|c|c|}
\hline$t_{\mathrm{M}}$ & $F_{M}$ & 1 & II & III & IV & v & VI & VII & \\
\hline \multirow[t]{2}{*}{0.063} & 0.17 & 0 & 0 & 0 & 0.05 & 0.27 & 0.07 & & Exp. \\
\hline & 0.143 & 0.002 & 0.031 & 0.018 & 0.089 & 0.206 & 48 & & heo. \\
\hline \multirow[t]{2}{*}{0.085} & 0.146 & 0 & 0 & 0 & 0.05 & 0.24 & $\begin{array}{l}0.06 \\
0.037\end{array}$ & $\begin{array}{l}0.6 b \\
0.560\end{array}$ & Exp. \\
\hline & 0.261 & 0.003 & 0.034 & 0.031 & 0.072 & $\begin{array}{l}0.263 \\
0.29\end{array}$ & $\begin{array}{l}0.031 \\
0.06\end{array}$ & 0.37 & Exp. \\
\hline 0.125 & $\begin{array}{l}0.28 \\
0.355\end{array}$ & $\begin{array}{l}0.03 \\
0.010\end{array}$ & $\begin{array}{l}0.07 \\
0.086\end{array}$ & $\begin{array}{l}0.06 \\
0.051\end{array}$ & $\begin{array}{l}0.12 \\
0.125\end{array}$ & 0.281 & 0.059 & 0.388 & Theo. \\
\hline \multirow[t]{2}{*}{0.184} & 0.36 & 0.03 & 0.09 & 0.09 & 0.18 & 0.31 & 0.09 & 0.25 & Exp. \\
\hline & 0.507 & 0.025 & 0.139 & 0.084 & 0.138 & 0.296 & 0.058 & 0.260 & Theo. \\
\hline \multirow[t]{2}{*}{0.400} & 0.595 & 0.12 & 0.25 & 0.14 & 0.15 & 0.17 & 0.03 & 0.04 & Exp. \\
\hline & 0.613 & 0.128 & 0.296 & 0.160 & 0.136 & 0.189 & 0.035 & 0.056 & Theo. \\
\hline \multirow[t]{2}{*}{0.408} & 0.629 & 0.14 & 0.25 & 0.15 & 0.16 & 0.17 & 0.06 & 0.07 & Exp. \\
\hline & 0.620 & 0.139 & 0.313 & 0.150 & 0.141 & 0.172 & 0.035 & 0.049 & Theo. \\
\hline \multirow[t]{2}{*}{0.512} & 0.69 & 0.20 & 0.31 & 0.13 & 0.15 & 0.11 & 0.06 & 0.05 & Exp. \\
\hline & 0.711 & 0.203 & 0.342 & 0.163 & 0.122 & 0.123 & 0.022 & 0.023 & Theo. \\
\hline \multirow[t]{2}{*}{0.779} & 0.854 & 0.45 & 0.31 & 0.13 & 0.06 & 0.05 & & & Exp. \\
\hline & 0.890 & 0.400 & 0.369 & 0.118 & 0.081 & 0.026 & 0.004 & 0.001 & Theor \\
\hline
\end{tabular}
Markov statistics). ${ }^{26}$ As can be seen, very good agreement is achieved between experimentally observed and theoretically calculated peak areas. As a result, the new peak assignment and a coisotacticity parameter of 0.39

Table 4. Experimentally observed (NMR) and theoretically calculated peak areas of the carbonyl carbon resonances of BA- and MMA-centred sequences ${ }^{2}$

a Predicted relative areas obtained by using the ultimate model for low conversion copolymers, and $r_{M}=2.279$ and $r_{\mathrm{B}}=0.395, \sigma_{\mathrm{MM}}=0.23, \sigma_{\mathrm{BM}}=0.39$ and the appropriate assignment for various initial feed compositions $f_{M}$. 
can be used for analysing all types of BA-MMA copolymers (low and high conversion solution or emulsion copolymers) in terms of triad sequences.

\section{${ }^{13}$ C NMR}

Assignment of the carbonyl carbon (MMA + BA). In Fig. 1 a $100 \mathrm{MHz}{ }^{13} \mathrm{C}$ NMR spectrum is shown of a BA-MMA copolymer $\left(F_{\mathrm{M}}=0.69\right)$. Owing to the improved resolution at higher magnetic fields, the carbonyl carbon resonance signals between $\delta=180$ and $174 \mathrm{ppm}$ can be divided into at least seven resonance signal groupings whose intensities change drastically with the composition, as can be seen in Fig. 2. As already mentioned, the pattern of the carbonyl resonance area of the BA-MMA copolymers is very similar to the earlier observed pattern of the carbonyl resonance area of the EA-MMA copolymers (Fig. 7 in Ref. 14). As a result, the same assignment has been applied to the BA-MMA system. The assignment of the carbonyl resonance signals is given in Table 3, not only for reasons of completeness, but also because one configurational sequence (mm MMA) is missing in the original assignment of the carbonyl resonances of San Roman and Valero ${ }^{14}$ for the EA-MMA system. It should be noted that the peak signals are assigned in terms of compositional triads and no configurations are taken into account. More fine splittings in the peak signals are observed, probably caused by configurations. These effects are not clear enough to make an accurate assignment.

In Table 4 the experimentally observed peak areas of the carbonyl region are presented, together with the calculated peak areas, obtained from the calculated triads and the isotacticity parameter from the literature, $\sigma_{\mathrm{mm}}=0.23,{ }^{27}$ and the coisotacticity parameter $\sigma_{\mathrm{bm}}=$ 0.39 from this work. The good agreement between the experimental and calculated values confirms the suggested assignment of the carbonyl resonance signals.

\section{CONCLUSIONS}

The proton NMR spectra of statistical BA-MMA copolymers at higher magnetic fields show more fine resonance splitting in the methoxy region, which enables us to make a more accurate assignment. The methoxy region is sensitive for MMA-centred sequences. There is a satisfactory agreement between experimental and theoretical peak areas over a wide range of copolymer compositions, based on the ultimate copolymerization model and a coisotacticity parameter $\sigma_{\mathrm{BM}}=0.39$. The reactivity ratios measured via proton NMR and calculated by the EVM method, $r_{M}$ and $r_{B}$, are 2.279 and 0.395 , respectively.

The ${ }^{13} \mathrm{C}$ NMR spectra of the BA-MMA copolymers, in particular the carbonyl resonance signals, were very similar to the ${ }^{13} \mathrm{C}$ NMR spectra of the EA-MMA copolymers. The same peak assignment for the carbonyl resonances was applied in terms of both MMA-centred and BA-centred triads, and very good agreement between experimental peak areas and theoretical calculated peak areas was achieved.

\section{ABBREVIATIONS OF COPOLYMERS}

$\begin{array}{ll}\text { AA } & \text { Acrylic acid } \\ \text { BA } & \text { Butyl acrylate } \\ \text { EA } & \text { Ethyl acrylate } \\ \text { HA } & \text { Heptyl acrylate } \\ \text { MA } & \text { Methyl acrylate } \\ \text { PA } & \text { Propyl acrylate } \\ \text { PhA } & \text { Phenyl acrylate }\end{array}$

BMA Butyl methacrylate

EMA Ethyl methacrylate

GMA Glycidyl methacrylate

MAA Methacrylic acid

MMA Methyl methacrylate

PMA Propyl methacrylate

(2na)MA 2-Naphthyl methacrylate

(dma)MA Dimethylamino methacrylate

(tnbt)MA Tri-n-butyltin methacrylate

PMMA Poly(methyl methacrylate)

\section{Acknowledgerments}

The authors thank Dr A. M. van Herk and Ir B. Manders for helping with some of the calculation procedures.

\section{REFERENCES}

1. R. Zeelenberg, personal communication, 1994.

2. S. Hvilsted, in Atlas de Polymer- und Kunststoffanalyse, Band 2, Teil b/1, p. 223, Carl Hanser Verlag (1988).

3. H. Angad Gaur, Recl. Trav. Chim. Pays-Bas, 110, 553 (1991).

4. E. Klesper, A. Johnsen, W. Gronski, F. W. Wehrli and W. Felix, Makromol. Chem. 176, 1071 (1975), and references cited therein; A. Johnsen, E. Klesper and T. Wirthlin, Makromol. Chem. 177, 2397 (1976).

5. M. F. Llauro, R. Spitz and C. Pichot, J. Macromol: Sci. Chem., A19, 881 (1983).

6. A. S. Brar and A. K. Saini, J. Appl. Polym. Sci., 32, 4607 (1986); A. S. Brar, G. S. Kapur and S. K. Dubey, Eur. Polym. J. 24, 807 (1988).
7. G. S. Kapur and A. S. Brar, Indian J. Chem., 30A, 493 (1991).

8. C. I. Simionescu, A. Natansohn and V.Percec, Colloid. Polym. Sci. 259, 697 (1981).

9. L. Merle and Y. Merle, Macromolecules 15, 360 (1982)

10. W. F. Manders, J. M. Bellama, R. B. Johanneses, E. J. Parks and F. E. Brinckman, J. Polym. Sci., Part A, 25, 3469 (1987).

11. A. S. Brar, E. Arunan and G. S. Kapur, Polym. J. 21. 689 (1989).

12. Y. Mori, A. Ueda, H. Tanzawa, K. Matsuzaki and H. Kobayashi, Makromol. Chem. 176, 699 (1975).

13. M. M. C. Lopez-Gonzalez, M. Fernandez-Garcia, J. M Barrales-Rienda, E. L. Madruga and C. Arias, Polymer 34, 3123 (1993). 
14. J. San Roman and M. Valero, Polymer 31, 1216 (1990)

15. J. C. Brosse, J. M. Gauthier and J. C. Lenain, Makromol. Chem. 184, 1379 (1983).

16. Y. E. Shapiro, N. A. Budanov, Z. V. Orlova and S. I. Kuchanov, Vysokomol. Soedin. Ser. B 31, 123 (1989).

17. J. San Roman and E. L. Madruga, Eur. Polym. J. 18, 481 (1982).

18. P. K. Dhal, G. N. Babu and R. K. Nanda, Macromolecules 17 , 1131 (1984)

19. G. H. J. van Doremaele, PhD Thesis Eindhoven University of Technology, 1990, Chapt. 4.

20. A. M. Aerdts, J. W. de Haan, A. L. German and G. P. M. van der Velden, Macromolecules 24, 1473 (1991); A. M. Aerdts, J. W. de Haan and A. L. German, Macromolecules 26, 1965 (1993).
21. G. H. J. Van Doremaele, A. L. German, N. K. de Vries and G. P. $M$. van der Velden, Macromolecules 23, 4206 (1990).

22. J. C. J. F. Tacx, G. P. M. van der Velden and A. L. German, J. Polym. Sci., Polym. Chem. Ed. 26, 1439 (1988).

23. M. Dube, R. Amin Samayei, A. Penlidis, K. F. O'Driscoll and P. M. Reilly, J. Polym. Sci. Polym. Chem. Ed. 29, 703 (1991).

24. A. M. van Herk, J. Chem. Educ. in press.

25. I. A. Maxwell, A. M. Aerdts and A. L. German, Macromolecules 26, 1956 (1993).

26. J. L. Koenig, Chemical Microstructure of Polymer Chains. Wiley, New York, (1980).

27. Y. Inoue, A. Nishioka and R. Chujo, Makromol. Chem. 156, 207 (1972). 